\title{
Boron-Lined Multitube Neutron Proportional Counter Test
}

ML Woodring

JH Ely

RT Kouzes

DC Stromswold

September 6, 2010

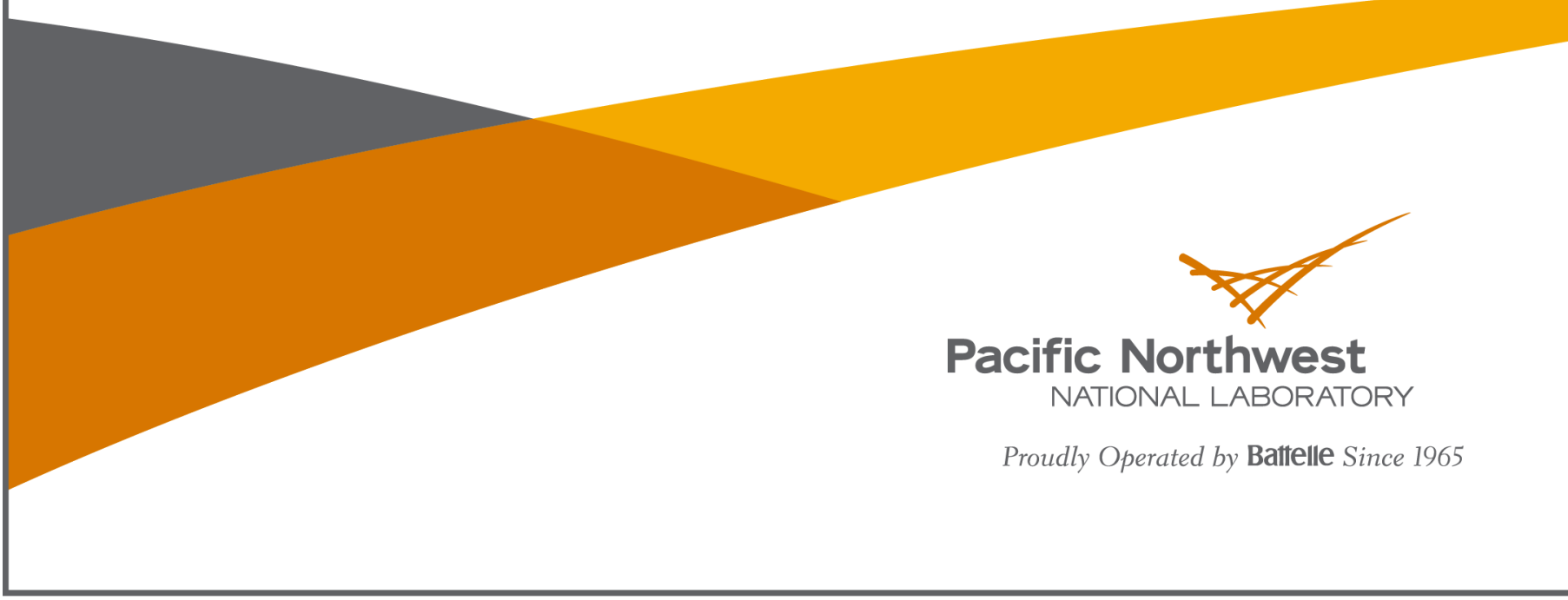




\title{
DISCLAIMER
}

This report was prepared as an account of work sponsored by an agency of the United States Government. Neither the United States Government nor any agency thereof, nor Battelle Memorial Institute, nor any of their employees, makes any warranty, express or implied, or assumes any legal liability or responsibility for the accuracy, completeness, or usefulness of any information, apparatus, product, or process disclosed, or represents that its use would not infringe privately owned rights. Reference herein to any specific commercial product, process, or service by trade name, trademark, manufacturer, or otherwise does not necessarily constitute or imply its endorsement, recommendation, or favoring by the United States Government or any agency thereof, or Battelle Memorial Institute. The views and opinions of authors expressed herein do not necessarily state or reflect those of the United States Government or any agency thereof.

\author{
PACIFIC NORTHWEST NATIONAL LABORATORY \\ operated by \\ BATTELLE \\ for the \\ UNITED STATES DEPARTMENT OF ENERGY \\ under Contract DE-AC05-76RL01830
}

Printed in the United States of America
Available to DOE and DOE contractors from the Office of Scientific and Technical Information,
P.O. Box 62, Oak Ridge, TN 37831-0062;
ph: (865) 576-8401
fax: $(865)$ 576-5728
email: reports@adonis.osti.gov

\begin{abstract}
Available to the public from the National Technical Information Service, U.S. Department of Commerce, 5285 Port Royal Rd., Springfield, VA 22161 ph: (800) 553-6847 fax: $(703) 605-6900$ email: orders@ntis.fedworld.gov online ordering: http://www.ntis.gov/ordering.htm
\end{abstract}

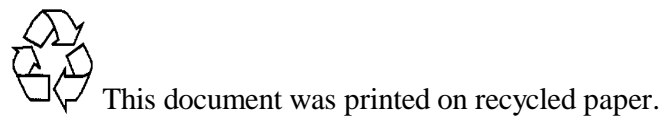




\title{
Boron-Lined Multitube Neutron Proportional Counter Test
}

\author{
ML Woodring \\ JH Ely \\ RT Kouzes \\ DC Stromswold
}

September 6, 2010

Pacific Northwest National Laboratory

Richland, Washington 99352 


\section{Executive Summary}

Radiation portal monitors used for interdiction of illicit materials at borders include highly sensitive neutron detection systems. The main reason for having neutron detection capability is to detect fission neutrons from plutonium. The currently deployed radiation portal monitors (RPMs) from Ludlum and Science Applications International Corporation (SAIC) use neutron detectors based upon ${ }^{3} \mathrm{He}$-filled gas proportional counters, which are the most common large neutron detector. There is a declining supply of ${ }^{3} \mathrm{He}$ in the world, and thus, methods to reduce the use of this gas in RPMs with minimal changes to the current system designs and sensitivity to cargo-borne neutrons are being investigated.

Four technologies have been identified as being currently commercially available, potential alternative neutron detectors to replace the use of ${ }^{3} \mathrm{He}$ in RPMs. These technologies are:

1) Boron trifluoride $\left(\mathrm{BF}_{3}\right)$-filled proportional counters,

2) Boron-lined proportional counters,

3) Lithium-loaded glass fibers, and

4) Coated non-scintillating plastic fibers.

In addition, a few other companies have detector technologies that might be competitive in the near term as an alternative technology. Reported here are the results of tests of a boron-lined, "multitube" proportional counter manufactured by Centronic Ltd. (Surry, U.K. and Houston, TX). In this testing, we measured the required performance for neutron detection efficiency and gamma-ray rejection capabilities of the detector.

The Centronic neutron detector has been tested and compared to ${ }^{3} \mathrm{He}$ as a possible alternative neutrondetection technology. The detector differs from standard boron-lined tubes in that it contains several small detectors ("tubelets") inside a cylindrical housing.

The tests were conducted on a single, short detector of dimensions $63.5 \mathrm{~mm} \times 312 \mathrm{~mm}$ (diameter $\mathrm{x}$ length) mounted in a standard polyethylene moderator box that normally holds the ${ }^{3} \mathrm{He}$ tubes in a RPM. Results suggest that neutron-detection efficiency comparable to that of existing ${ }^{3} \mathrm{He}$ detectors may be difficult to achieve, even when the length is extended to the match that of conventional tubes and multiple tubes are used. Tests are needed with full-scale tubes to determine if it is possible to achieve the required sensitivity in spite of the interaction among the tubes resulting in neutron-flux suppression.

Test results indicate that adequate intrinsic gamma ray efficiency (gamma ray rejection) is obtained for gamma exposure rates up to $100 \mathrm{mR} / \mathrm{hr}$. The gamma rejection factor is estimated to be on the order of $10^{-8}$ for exposure rates up to $100 \mathrm{mR} / \mathrm{hr}$, which is about that obtained for ${ }^{3} \mathrm{He}\left(\sim 10^{-8}\right)$.

The GARRn value at a ${ }^{60} \mathrm{Co}$ exposure rate of $10 \mathrm{mR} / \mathrm{hr}$ is within the desired range for the small system tested. A larger system with a total neutron efficiency designed for use as a replacement for the ${ }^{3} \mathrm{He}-$ based system in deployed systems needs to be evaluated to see if the GARRn value remains in the acceptable range.

The system tested demonstrates that this technology might meet the neutron detection requirements for homeland security applications, but testing of a multi-tube system is required. 


\section{Acronyms and Abbreviations}

ANSI
cps
GARRn
mR/h
PNNL
RPM
RSP
SAIC

ANSI

American National Standards Institute

Counts per second

Gamma Absolute Rejection Ratio in the presence of neutrons

Milli-Roentgen per hour

Pacific Northwest National Laboratory

Radiation Portal Monitor

Radiation Sensor Panel

Science Applications International Corporation 


\section{Contents}

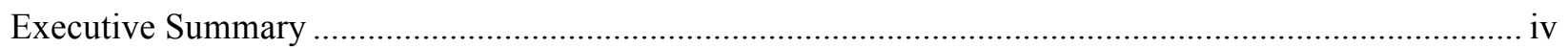

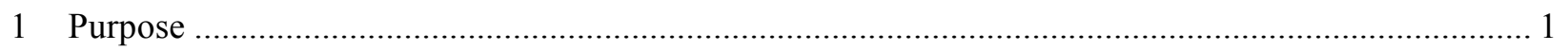

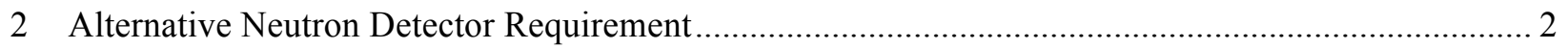

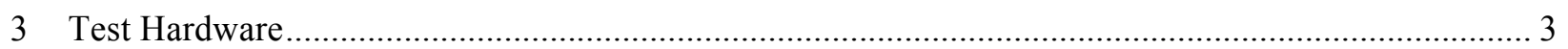

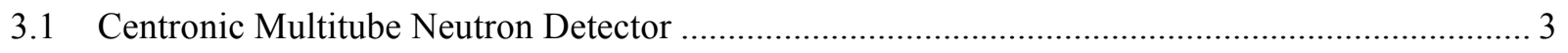

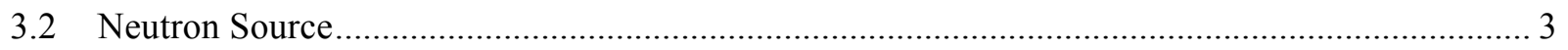

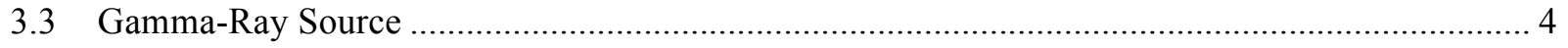

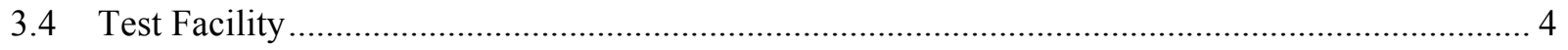

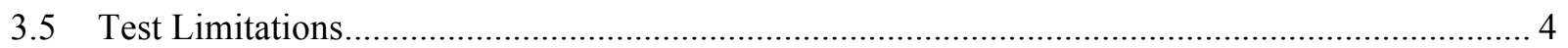

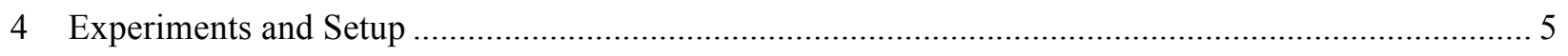

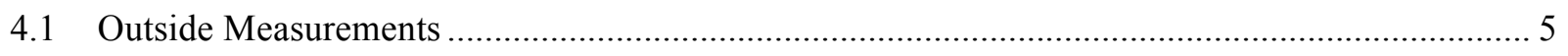

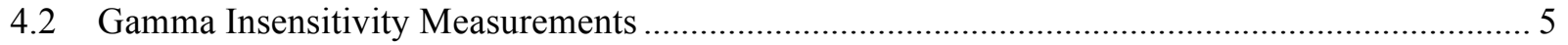

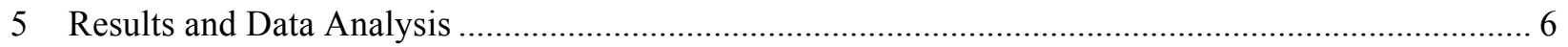

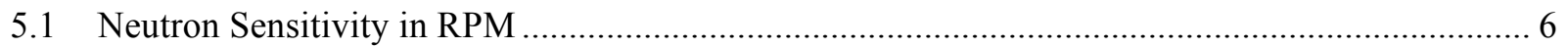

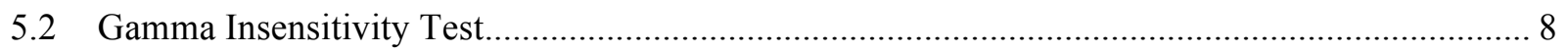

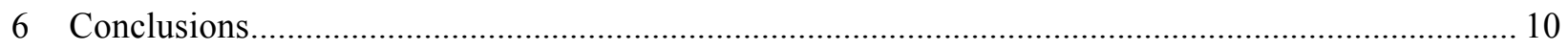

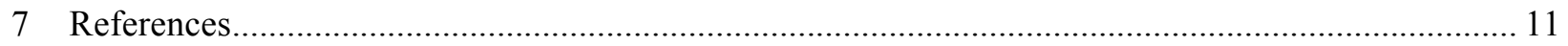




\section{Figures and Tables}

\section{Figures}

Figure 3-1: Centronic multitube proportional counter. ................................................................... 3

Figure 5 -1. Spectra from Centronic multitube detector and ${ }^{3} \mathrm{He}$ in RPM $\left({ }^{3} \mathrm{He}\right.$ counts divided by 10$) \ldots \ldots . .6$

\section{Tables}

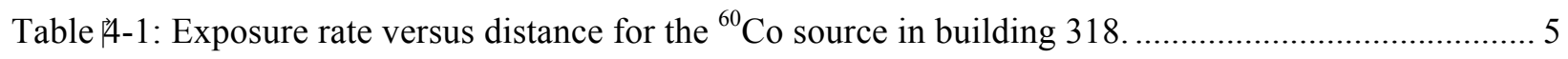

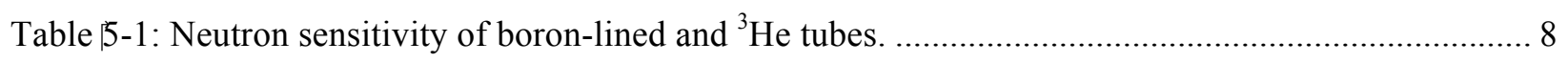

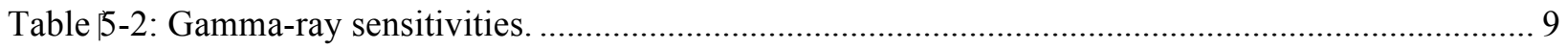




\section{Purpose}

Radiation portal monitor (RPM) systems used for interdiction of illicit materials at borders include highly sensitive neutron detection systems. The main reason for having neutron detection capability is to detect fission neutrons from plutonium. The currently deployed radiation portal monitors from Ludlum and Science Applications International Corporation (SAIC) use neutron detectors based upon ${ }^{3} \mathrm{He}$-filled gas proportional counters, which are the most common large neutron detector.

Within the last few years, the amount of ${ }^{3} \mathrm{He}$ available for use in gas proportional counter neutron detectors has become more restricted, while the demand has significantly increased, especially for homeland security applications (Kouzes 2009). In the near future, limited supply is expected to curtail the use of ${ }^{3} \mathrm{He}$; therefore, alternative neutron detection technologies are being investigated for use in the radiation portal monitor systems being deployed for border security applications (Van Ginhoven 2009).

From a survey of technologies, only four technologies have been identified as currently commercially available, potential alternative neutron detectors to replace the use of ${ }^{3} \mathrm{He}$ in RPMs in the near-term. These technologies are:

1) Boron trifluoride $\left(\mathrm{BF}_{3}\right)$-filled proportional counters,

2) Boron-lined proportional counters,

3) Lithium-loaded glass fibers, and

4) Coated non-scintillating plastic fibers).

In addition, a few other companies have detector technologies that might be competitive in the near term as an alternative technology. Reported here are the results of tests by Pacific Northwest National Laboratory (PNNL) of a boron-lined "multitube" proportional counter (manufactured by Centronic, Ltd. of Surrey, U.K. and Houston, TX). This detector is a short cylinder containing 14 multitubes. Testing of other designs of boron-lined detectors has been reported previously (Lintereur 2009; Kouzes 2010). This testing measured the performance of these tubes against the required neutron detection efficiency and gamma ray rejection capabilities. The measurements made as part of this testing include:

1. Response of the system to moderated and un-moderated neutrons

2. Response of the system to a high gamma-ray exposure rate to measure gamma sensitivity and GARRn (Kouzes et al., 2009) 


\section{Alternative Neutron Detector Requirement}

A neutron-detection system for replacement of the current neutron detectors in a standard ${ }^{3} \mathrm{He}-$ based RPM must fit within the space occupied by the present ${ }^{3} \mathrm{He}$-based neutron detection system $[0.114 \mathrm{~m}$ deep $\mathrm{x}$ $0.304 \mathrm{~m}$ wide $\mathrm{x} 2.18 \mathrm{~m}$ tall $(4.5$ in. $\times 12$ in. $\times 85.7$ in. $)]$ in the SAIC RPM system.

The standard ${ }^{3} \mathrm{He}$-based systems were purchased under a specification (Stromswold et al., 2003) that requires a single radiation sensor panel (RSP) to meet the following requirements:

"A ${ }^{252} \mathrm{Cf}$ neutron source will be used for testing neutron sensor sensitivity:

- To reduce the gamma-ray flux, the source shall be surrounded by at least $5 \mathrm{~mm}$ of lead. To moderate the neutron spectrum, $25 \mathrm{~mm}$ of polyethylene shall be placed around the source.

- The absolute detection efficiency for such a ${ }^{252} \mathrm{Cf}$ source, located $2 \mathrm{~m}$ perpendicular to the geometric midpoint of the neutron sensor, shall be greater than $2.5 \mathrm{cps} / \mathrm{ng}$ of ${ }^{252} \mathrm{Cf}$. The neutron detector center shall be $1.5 \mathrm{~m}$ above grade for this test. (Note: 10 nanograms of ${ }^{252} \mathrm{Cf}$ is equivalent to 5.4 micro-Ci or $2.1 \times 10^{4} \mathrm{n} / \mathrm{s},{ }^{1}$ since ${ }^{252} \mathrm{Cf}$ has a $3.092 \%$ spontaneous fission (SF) branch and 3.757 neutrons/SF.)

- The neutron detector shall not generate alarms due to the presence of strong gamma-ray sources. The ratio of neutron sensor gamma-ray detection efficiency to neutron detection shall be less than 0.001."

To evaluate the performance of alternate neutron detectors compared to what is currently deployed three criteria are considered: 1) absolute neutron detection efficiency, 2) intrinsic efficiency of gamma rays detected as neutrons, and 3) Gamma Absolute Rejection Ratio in the presence of neutrons (GARRn) (Kouzes et al., 2009).

The absolute neutron detection efficiency $\left(\epsilon_{\text {abs n }}\right)$ required is that previously specified $(2.5 \mathrm{cps} / \mathrm{ng}$ from a ${ }^{252} \mathrm{Cf}$ source at $2 \mathrm{~m}$ in a specified pig). The intrinsic efficiency of gammas detected as neutrons $\left(\epsilon_{\text {int }} \mathrm{n}\right)$ is the number of events that are counted as neutrons in the presence of a gamma source divided by the number of photons hitting the detector area, and shall be less than $10^{-6}$ at an exposure rate of $10 \mathrm{mR} / \mathrm{h}$. GARRn is the number of events that are counted as neutrons $\left(\epsilon_{\mathrm{abs} \gamma \mathrm{n}}\right)$ in the presence of both a gamma ray and neutron source divided by the number of neutrons recorded without the gamma ray source $\left(\epsilon_{\mathrm{abs} n}\right)$, the requirement for this parameter is that $0.9 \leq \mathrm{GARRn} \leq 1.1$ at a $10 \mathrm{mR} / \mathrm{h}$ gamma exposure rate.

In addition, these systems are required to meet all aspects of the ANSI N42.35 standard (ANSI 2006). A summary of neutron detection systems in RPMs can be found in a PNNL report (Kouzes et al., 2007).

\footnotetext{
${ }^{1} 2.3 \times 10^{4} \mathrm{n} / \mathrm{s}$ is the currently used best known value
} 


\section{Test Hardware}

\subsection{Centronic Multitube Neutron Detector}

The Centronic detector (Tsorbatzoglou 2010) is a variation on conventional boron-lined proportional counters that are cylindrical and contain a single anode wire. The modified detector as tested is a short detector containing 14 "multitubes" created by drilling holes axially in an aluminum rod. Each multitube has an anode wire, and all of these wires are connected to a single output. The physical dimensions of the detector are $63.5-\mathrm{mm}$ diameter $\times 312-\mathrm{mm}$ length $(2.5 \mathrm{in} . \mathrm{x} 12.3 \mathrm{in})$. The individual multitubes inside the detector are $12.7-\mathrm{mm}$ diameter $\mathrm{x} 244-\mathrm{mm}$ length $(0.5 \mathrm{in} . \mathrm{x} 9.6 \mathrm{in}$.). Figure 3.1 shows the detector.

During the tests the detector was located in a polyethylene moderator box that normally houses a ${ }^{3} \mathrm{He}$ tube in RPMs. This moderator has external dimensions $0.114 \mathrm{~m}$ deep x $0.304 \mathrm{~m}$ wide $\mathrm{x} 2.18 \mathrm{~m}$ tall (4.5 in. $\times$ 12 in. $\times 85.7$ in.

The detector has ${ }^{10} \mathrm{~B}$ on the inner walls of the multitubes. Thermal neutrons interact with the ${ }^{10} \mathrm{~B}$ resulting in the ${ }^{10} \mathrm{~B}(\mathrm{n}, \alpha)^{7} \mathrm{Li}$ reaction, and the charged particles produced cause ionization in the gas $\left(\mathrm{Ar}\right.$ and $\left.\mathrm{CO}_{2}\right)$ that fills the detector.

Electrical pulses from the tube were counted with conventional laboratory electronics (Ortec 142AH preamplifier, Ortec 472 amplifier, and Amptek Pocket multichannel analyzer).

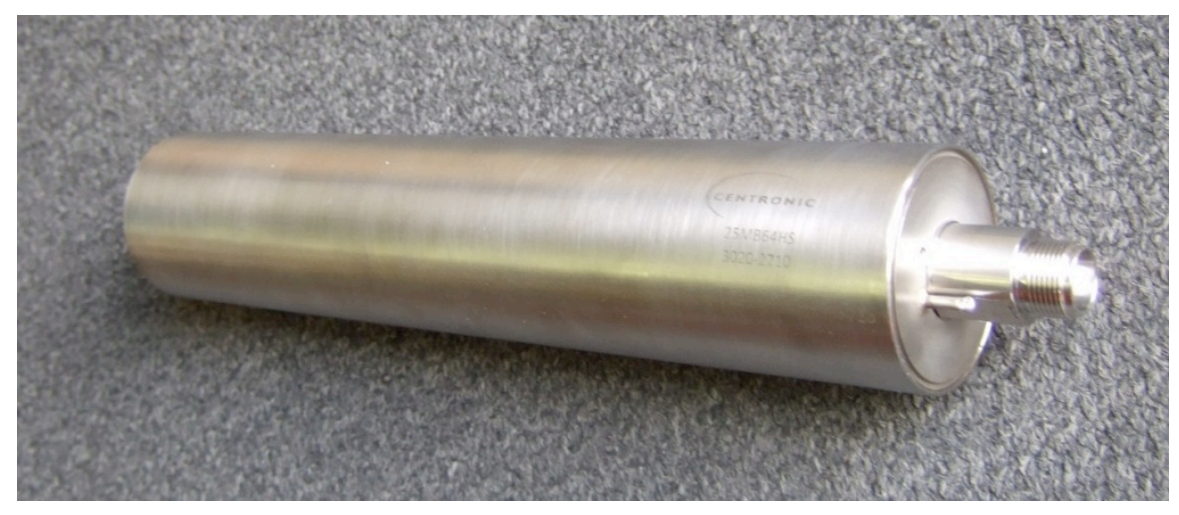

Figure 3-1: Centronic multitube proportional counter.

\subsection{Neutron Source}

The neutron source used for this test was ${ }^{252} \mathrm{Cf}$, with a half-life of 2.645 years. The source was purchased from Isotope Products Laboratory (IPL) and given a PNNL ID of 60208-44. The source was measured by IPL to be $21.91 \pm 1.25 \mu \mathrm{Ci}$ on October 1,2009 . The source used was estimated to be $17.8 \mu \mathrm{Ci}$ during the tests (July 23, 2010). This activity corresponds to $32.9 \mathrm{ng}$ and an emanation rate of $7.7 \times 10^{4} \mathrm{n} / \mathrm{s}$ with the conversion factor stated in Section 2. This same neutron source was used when the gamma sensitivity of the detector was being tested.

The source was located inside $25 \mathrm{~mm}$ of polyethylene moderator outside of $5 \mathrm{~mm}$ of lead. 


\subsection{Gamma-Ray Source}

A ${ }^{60}$ Co gamma ray source located in the Radiological Calibrations Laboratory in Building 318 at PNNL was used for the gamma ray sensitivity test. The exposure rate as a function of distance from the ${ }^{60} \mathrm{Co}$ source was determined by staff at the facility. The source strength was $105.9 \mathrm{mCi}$ on July 14, 2010 .

\subsection{Test Facility}

The tests were performed at PNNL at the 331G Integration Test Facility and the 318 Radiological Calibrations Laboratory located in Richland, WA. The outside tests were performed at the $331 \mathrm{G}$ building at PNNL. The gamma-ray insensitivity measurements with the ${ }^{60} \mathrm{Co}$ source were performed inside building 318 .

\subsection{Test Limitations}

There were several limitations for this test and results may change with different conditions.

- Only one test location for each of the measurements was used, with the corresponding background. Since the testing was focused on net results (background subtracted) this should have little effect on the overall results.

- Only one detector system was tested. Results may change with different detector geometries.

- Uncertainty in the neutron source's strength (Section 3.2) was the main limitation to the test results. 


\section{Experiments and Setup}

\subsection{Outside Measurements}

Static measurements were made with the detector mounted in the polyethylene moderator box located inside a SAIC RSP panel. The neutron source was located on a tripod $2 \mathrm{~m}$ from the closed door of the RPM and at a height that positioned the source at the center of the detector.

Data were acquired over five-minute time intervals for background and with the source measurements. The acquired data were used to compare the Centronic detector efficiency with that of the ${ }^{3} \mathrm{He}$ tubes used in existing RPMs.

\subsection{Gamma Insensitivity Measurements}

The detector sensitivity for gamma rays was tested with a high-activity ${ }^{60} \mathrm{Co}$ source in Building 318 ; the gamma rays flooded the entire detector. Table 4-1 shows the source-to-detector-face distance for each of the indicated exposure rates.

Measurements were also made with the neutron source and the ${ }^{60} \mathrm{Co}$ source present simultaneously to determine the GARRn value and the gamma-ray rejection factor. For these indoor measurements, the neutron source was placed at $2 \mathrm{~m}$ from the back of the detector so as not to interfere with the gamma-ray beam.

Table 4-1: Exposure rate versus distance for the ${ }^{60} \mathrm{Co}$ source in building 318.

\begin{tabular}{|c|c|}
\hline $\mathbf{m R} / \mathbf{h}$ & Distance (m) \\
\hline 5 & 5.20 \\
\hline 10 & 3.68 \\
\hline 20 & 2.60 \\
\hline 50 & 1.64 \\
\hline 100 & 1.16 \\
\hline
\end{tabular}

The ${ }^{60} \mathrm{Co}$ gamma-sensitivity measurements were made with the detector, inside its polyethylene moderator box, placed horizontally on top of two stands at the height of the gamma ray source. The detector was moved to different distances from the source to obtain the desired exposure rates on the front face when the source was in position. Five-minute measurements were made for different configurations at each position:

1. Background

2. ${ }^{60} \mathrm{Co}$ source in place

3. ${ }^{60} \mathrm{Co}$ source in place and the neutron source located on a tripod $2 \mathrm{~m}$ from the back of the detector. 


\section{Results and Data Analysis}

\subsection{Neutron Sensitivity in RPM}

Figure 5-1 shows the pulse-height and background spectra obtained when the ${ }^{252} \mathrm{Cf}$ source was located 2 $\mathrm{m}$ in front of the RPM. The figure also shows data collected when a ${ }^{3} \mathrm{He}$ tube was in the RPM instead of the Centronic tube. For both detectors the large numbers of counts at low channel numbers are from gamma rays and electronic noise, and the upper portions are the neutron signals.

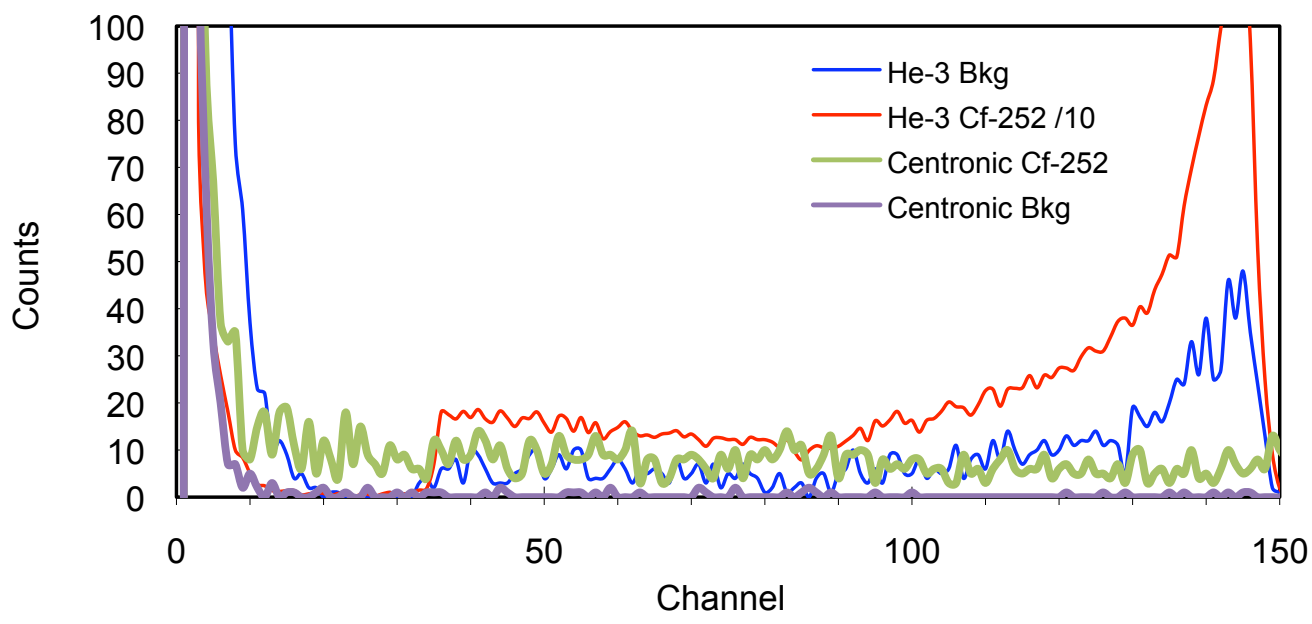

Figure 5-1. Spectra from Centronic multitube detector and ${ }^{3} \mathrm{He}$ in RPM $\left({ }^{3} \mathrm{He}\right.$ counts divided by 10$)$. 
Table 5-1 shows integrated counts and calculated count rates and neutron sensitivities from the spectra for the boron-lined detector and ${ }^{3} \mathrm{He}$. In these spectra, the integration starts at channel 12 for the boron-lined detector and at channel 30 for ${ }^{3} \mathrm{He}$. As shown in the Table 5-1, the neutron counting efficiency for the detector is $0.12 \mathrm{cps} / \mathrm{ng}$ for the short detector. If we assume a linear increase in efficiency as the tube length is increased to the normal $1.82-\mathrm{m}$ length used in RPMs, the efficiency should be about 7.5 times larger, or $0.9 \mathrm{cps} / \mathrm{ng}$.

The requirement for the replacement neutron detector technology to provide at least $2.5 \mathrm{c} / \mathrm{s} / \mathrm{ng}$, indicating that several multitube detectors are required to meet the sensitivity presently achieved by a single ${ }^{3} \mathrm{He}$ tube. However, it is not clear that adequate space exists in the moderator box to contain a sufficient number of tubes because the interaction among tubes results in neutron-flux suppression. Tests with multiple, full-length detectors are needed to determine if it is possible to achieve the required sensitivity in spite of the interaction among the tubes resulting in neutron-flux suppression. 
Table 5-1: Neutron sensitivity of boron-lined and ${ }^{3} \mathrm{He}$ tubes.

\begin{tabular}{|l|c|c|}
\hline & $\begin{array}{c}\text { Centronic } \\
\text { Boron-lined } \\
\text { Multitube } \\
\text { (short detector) }\end{array}$ & ${ }^{3} \mathbf{H e}$ \\
\hline${ }^{252} \mathrm{Cf}$ & 1276 & 29,605 \\
\hline Background & 69 & 1131 \\
\hline Net counts & 1207 & 28,474 \\
\hline Net count rate (c/s) & 4.0 & 95 \\
\hline Counts/s/ng & 0.12 & 2.9 \\
\hline
\end{tabular}

\subsection{Gamma Insensitivity Test}

Spectra obtained with the detector in the gamma-ray facility were processed to measure the number of "apparent neutrons" actually caused by gamma rays, again starting the integration at channel 12 .

The gamma-ray flux at the detector was estimated from the effective activity, which was calculated from the measured exposure rate at the detector, two gamma rays per decay, and the gamma factor for ${ }^{60} \mathrm{Co}$ $\left(13.2 \mathrm{R} \cdot \mathrm{cm}^{2} / \mathrm{hr} \cdot \mathrm{mCi}\right)$. The effective activity is defined as the source activity that is required to produce the measured exposure rate at the detector distance from the source. The effective activity was used to calculate the flux of gamma rays on the effective surface area of the detector.

Values for the intrinsic gamma ray efficiency and GARRn can be estimated from the calculated photon flux and the un-scaled neutron efficiency. The neutron efficiency used to calculate GARRn for each gamma exposure was the efficiency associated with each particular measurement. Thus, any geometric effects are divided out of the results. The results of the measurements are given in Table 5-2. For each exposure rate from 5 to $100 \mathrm{mR} / \mathrm{h}$, the table shows the background count rate, the net (backgroundsubtracted) count rates for the gamma-ray source, the neutron source, and the combined neutron and gamma ray sources, and the ${ }^{252} \mathrm{Cf}$ count rate per nanogram. The GARRn (Table 5-2 Error! Reference source not found. $)$ is seen to be within the acceptable range $(0.9 \leq$ GARRn $\leq 1.1)$ for exposure rates up to $10 \mathrm{mR} / \mathrm{h}$.

The intrinsic gamma-ray efficiency(Table 5-2) is better than the required value of $10^{-6}$ for exposure rates up to $100 \mathrm{mR} / \mathrm{hr}$. The value for the Gamma Rejection was calculated by multiplying the net gamma-ray count rate by 7.5 to scale up to a full-length detector, and then dividing by the rate of gamma rays striking the polyethylene moderator in which the detector was located.

Measurements of GARRn and gamma ray rejection in a full-scale system are necessary, since pileup effects are important to these parameters and may not scale linearly. However, tests with other boronlined proportional tubes indicate that the requirements should be achievable. 
Table 5-2: Gamma-ray sensitivities.

\begin{tabular}{|cccccc|c|}
\hline $\begin{array}{c}\text { mR/h } \\
\text { Position }\end{array}$ & $\begin{array}{c}\text { Background } \\
\text { cps }\end{array}$ & $\begin{array}{c}\text { Net } \\
\text { Gamma } \\
\text { cps }\end{array}$ & $\begin{array}{c}\text { Net } \\
{ }^{\mathbf{5} 2} \mathbf{C f} \\
\mathbf{c p s}\end{array}$ & $\begin{array}{c}\text { Net } \\
\text { Gamma }+\mathbf{C f}\end{array}$ & $\begin{array}{c}\text { cps } \\
\text { GARRn }\end{array}$ & $\begin{array}{c}\text { Gamma } \\
\text { Rejection }\end{array}$ \\
5 & 0.07 & 0.10 & 3.22 & 3.09 & 0.96 & $1 \times 10^{-8}$ \\
10 & 0.09 & 0.24 & 3.04 & 3.21 & 1.06 & $2 \times 10^{-8}$ \\
20 & 0.09 & 0.69 & 3.11 & 3.65 & 1.17 & $2 \times 10^{-8}$ \\
50 & 0.09 & 3.09 & 3.09 & 6.37 & 2.06 & $4 \times 10^{-8}$ \\
100 & 0.10 & 13.99 & 3.09 & 17.81 & 5.77 & $9 \times 10^{-8}$ \\
\hline
\end{tabular}




\section{Conclusions}

A short Centronic multitube neutron detector has been tested and compared to ${ }^{3} \mathrm{He}$ as a possible alternate to ${ }^{3} \mathrm{He}$ neutron detection technology.

Results show that the neutron detection efficiency is approximately $0.9 \mathrm{cps} / \mathrm{ng}$ when extrapolated to the normal length of a single detector tube used in RPMs, a value significantly less than the required 2.5 $\mathrm{cps} / \mathrm{ng}$. It is not clear that adding multiple detectors result in the desired detection value because of a scavenging interaction among the multiple detectors that would suppress the available neutron flux. Tests need to be conducted with multiple, full-length detectors to determine their combined performance.

Test results indicate that these detectors have adequate intrinsic gamma ray efficiency (gamma-ray rejection) for gamma exposure rates up to $100 \mathrm{mR} / \mathrm{hr}$. The gamma rejection factor is on the order of $10^{-9}$ for dose rates up to $100 \mathrm{mR} / \mathrm{hr}$, which is greater than that obtained for ${ }^{3} \mathrm{He}\left(\sim 10^{-8}\right)$.

The GARRn value at a ${ }^{60} \mathrm{Co}$ exposure rate of $10 \mathrm{mR} / \mathrm{hr}$ is within the desired range. 


\section{References}

ANSI. 2006. American National Standard for Evaluation and Performance of Radiation Detection Portal Monitors for Use in Homeland Security. Technical Report. ANSI 42.35, American Nuclear Standards Institute, Washington, D.C.

Ely J, Kouzes RT, Lintereur A, Schweppe J, Siciliano E, and Woodring M. 2009. BF 3 Neutron Detector Testing and Comparison to ${ }^{3} \mathrm{He}$. PNNL-18581, Pacific Northwest National Laboratory, Richland, Washington.

Ely J, D Stromswold, and C Shepard. 2003. Radiation Portal Monitor Measurements. PIET-43741-TM014, PNNL-14110, Pacific Northwest National Laboratory, Richland, Washington.

Kouzes RT, Ely J, Lintereur A, Stephens D. 2009. Neutron Detector Gamma Insensitivity Criteria. PNNL -18903, Pacific Northwest National Laboratory, Richland, Washington.

Ely J and C Shepard. 2004. Test and Evaluation of the SAIC/Exploranium RPM8 Portal Monitor System. PIET-43741-TM-161, PNNL-16865, Pacific Northwest National Laboratory, Richland, Washington.

Kouzes RT, J Ely, and E Siciliano. 2007. Neutron Alarm Algorithms for Deployed RPMs. PIET-43741TM-663, PNNL-17101, Pacific Northwest National Laboratory, Richland, Washington.

Kouzes, RT, JH Ely, PE Keller, RJ McConn, and ER Siciliano. 2008. "Passive Neutron Detection for Interdiction of Nuclear Material at Borders." Nuclear Instruments and Methods in Physics Research Section A: Accelerators, Spectrometers, Detectors and Associated Equipment 584(2-3): 383-400.

Kouzes RT, ER Siciliano. 2009. ${ }^{3}$ He Neutron Detector Modification and BF 3 Comparison. PIET-43741TM-838, PNNL-18667, Pacific Northwest National Laboratory, Richland, Washington.

Kouzes, RT, 2009. “The ${ }^{3} \mathrm{He}$ Supply Problem," Pacific Northwest National Laboratory Report PNNL18388.

Kouzes RT, JH Ely, DC Stromswold 2010. Boron-Lined Straw-Tube Neutron Detector Test. PNNL19600, Pacific Northwest National Laboratory, Richland, Washington.

Lintereur AT, RT Kouzes, JH Ely, LE Erikson, ER Siciliano. 2009. Boron Lined Neutron Detector Measurements. PNNL-18938, Pacific Northwest National Laboratory, Richland, Washington.

Stromswold D, J Ely, R Kouzes, J Schweppe. 2003. Specifications for Radiation Portal Monitor Systems Revision 6.7. PIET-43741-TM-017, Pacific Northwest National Laboratory, Richland, Washington.

Tsorbatzoglou K and RD McKeag. 2010. "Novel and Efficient ${ }^{10} \mathrm{~B}$ Lined Tubelet Detector as a Replacement for ${ }^{3} \mathrm{He}$ Neutron Proportional Counters." 2010 Symposium on Radiation Measurements and Applications, May 2010, Univ. Michigan, Ann Arbor, MI, Paper 0452.

Van Ginhoven, RM, RT Kouzes, DL Stephens, 2009. “Alternative Neutron Detector Technologies for Homeland Security,” Pacific Northwest National Laboratory Report PNNL-18471. 


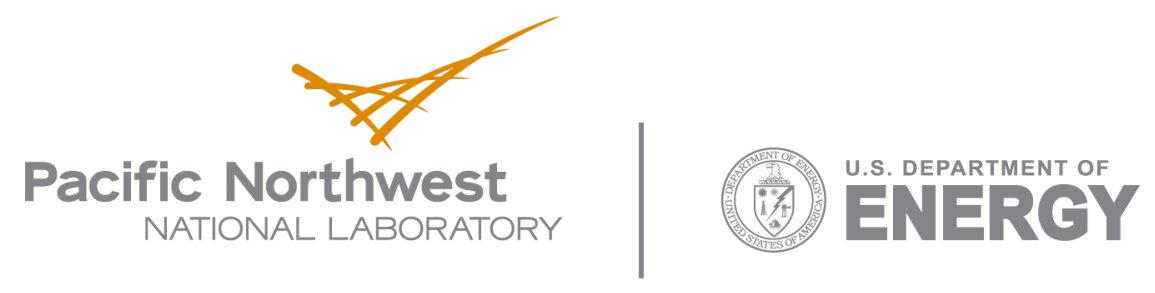

902 Battelle Boulevard

P.O. Box 999

Richland, WA 99352

1-888-375-PNNL (7665)

www.pnl.gov 